\title{
Lagrangian Surface Circulation in the Gulf of California from a 3D Numerical Model
}

\author{
O. Q. Gutiérrez, S. G. Marinone*, and A. Parés-Sierra.
}

Departamento de Oceanografía Física

Centro de Investigación Cientifíca y de Educación Superior de Ensenada

Km 107 carretera Tijuana-Ensenada

Ensenada, Baja California, México. C. P. 22860.

*Corresponding author Fax 52-646-1750547

E-mail address: marinonedcicese.mx

\begin{abstract}
The surface circulation of the Gulf of California was studied from a Lagrangian point of view using the results of a 3D numerical model. The advection of particles, whose depth is fixed, was carried out for annual and monthly periods with 710 particles homogeneously distributed over the gulf. An anticyclonic circulation was found at the northern region from October to May and in the central and southern regions during May and from October to November; cyclonic circulation was found in the entire gulf from July to August. This circulation pattern agrees with direct measurements of drifters in the northern region. During the cyclonic period the particles from the central and southern regions travel to the northern basin where they are trapped by a gyre for more than a month. On the other hand, during the anticyclonic period the particles flow to the southern part of the gulf. Some particles escape to the Pacific Ocean and others remain in the gulf and return to the northern part during the cyclonic period. The principal gyre that appears on the center of the northern gulf in both cyclonic and anticyclonic periods traps particles for more than 30 days in a radius of $50 \mathrm{~km}$. In the central and southern regions, a trapping zone was found in the peninsula side, where the particles travel less than $100 \mathrm{~km}$ in 30 days. On the other hand, over the continental coast there is a rapid transit zone. The particles escape only during the anticyclonic period.
\end{abstract}

Key words: Gulf of California, Lagrangian, seasonal, circulation, residence times. 


\section{Introduction}

The Gulf of California (hereafter GC), located in the northwest of Mexico, is a narrow shelf sea of approximately $1100 \mathrm{~km}$ length and $150 \mathrm{~km}$ width (Fig. 1). In the north the gulf is shallow $(\sim 120$ $\mathrm{m})$, then a region of large islands follows to the south: Angel de la Guarda and Tiburon islands. From there to the mouth the gulf becomes very deep (some of its basins have more than $2000 \mathrm{~m}$ depth). The seasonal variability of the GC is due to the seasonality of the main forcing agents: the Pacific Ocean at the gulf's entrance (Castro et al., 1994; Ripa, 1997), the monsoon wind regime (Badan et al., 1991), and the air-sea heat exchange (Beier, 1999; Marinone, 2003). In addition, Paden et al. (1991) suggest that tidal mixing also presents a considerable seasonal signal. Ripa $(1990,1997)$ proposed that the Pacific Ocean forces the gulf in the annual frequency by means of an internal baroclinic Kelvin wave of annual period which enters the GC on the eastern coast and then traverses cyclonically around the entire coastline. The hypothesis has been proved to explain the seasonal circulation and the balances of temperature and salinity (Beier, 1997; PalaciosHernández et al., 2002; Berón-Vera and Ripa, 2000 and 2002).

The best-known feature of the circulation in the GC is the large-scale seasonally reversing gyre in the northern gulf, documented by Lavín et al. (1997) with satellite tracked drifters, by Carrillo et al. (2002) from geostrophic calculations, and by Palacios-Hernández et al. (2002) with current meters. The cyclonic gyre lasts about 4 months (June to September) and the anticyclonic one about 6 months (November to April). In the southern gulf, there are no equivalent observations, but estimates from ships drift and from the distributions of temperature and salinity indicate surface outflow during winter and inflow during summer, mass conservation requiring a compensating 
flow at depth (Bray, 1988). At the mouth of the gulf, different studies, mainly in winter, show horizontal cyclonic currents of $10 \mathrm{~cm} \mathrm{~s}^{-1}$ reaching depths greater than $1000 \mathrm{~m}$ (Roden, 1972; Collins et al., 1997; Castro, 2001).

Beier (1997) found two well-defined gyres separated by the islands region. Marinone (2003) shows that an anticyclonic gyre exists over the San Pedro Martir Basin during most of the year.

These patterns of circulation in the gulf are based mainly on numerical simulations, which are Eulerian and not adequate to study processes of Lagrangian nature (e.g., origin and final destination of tracers, paths followed by larvae, etc.). Velasco Fuentes and Marinone (1999) showed that the main gyre in the northern part traps particles for more than two months, while a jet along the coast in the southern part advects particles for hundreds of kilometers. Their study was limited to a nonlinear two-dimensional model, forced only with tides and uniform winds along the gulf.

The main goal of this work is to use the results of the 3D numerical model of the gulf reported by Marinone (2003) to study the surface seasonal circulation of the gulf from a Lagrangian point of view. The study is limited to the use of the horizontal velocity components. The vertical velocity component is not used and, therefore, the results do not represent the real advective path of fluid parcels, but that of drifters tied to a specific depth, like those reported by Lavín et al. (1997). The results help us understand the behavior of the drifters and to "test" the model outputs by comparing them to observations. From the drifters/particles trajectories, residence times, and trapping/escaping zones as function of the seasonal circulation will be determined. These parameters are very useful 
in the study of particle dispersion, like organism larvae (i.e. Bartsch, 1993; Peterman et al. 1994) or contaminants.

\section{Model, boundary conditions, and experiments}

The trajectories of the particles were obtained by time-integrating the horizontal velocity field. This velocity field was obtained from the layerwise vertically integrated Hamburg Shelf Ocean Model (HAMSOM) three-dimensional baroclinic model developed by Bakhaus (1985). The model equations are solved semi-implicitly with fully prognostic temperature and salinity fields, thus allowing time-dependent baroclinic motion. The model domain has a mesh size of $2.5^{\prime} \times 2.5^{\prime}(\sim 3.9$ $\mathrm{km} x \sim 4.6 \mathrm{~km}$ ) in the horizontal, and twelve layers in the vertical with nominal lower levels at 10, $20,30,60,100,150,200,250,350,600,1000$, and $4000 \mathrm{~m}$. The model is described in detail in several papers (Backhaus, 1983, 1985; Crean et al., 1988; Stronach et al., 1993; Marinone et al., 1996; Rady et al., 1998), to which the reader is referred. The implementation of the model for the Gulf of California is described by Marinone (2003), who focused on the mean and seasonal global residual circulation, after showing that the model reproduces the main seasonal signals of the surface temperature, the heat balance and the tidal elevation.

The model is forced with the most important tidal constituents (M2, S2, N2, K2, K1, O1, P1, Ssa, and Sa). The temperature and salinity fields are prescribed at the gulf's entrance cross-section using the available historical database. Boundary gridpoints are interpolated for each month of the year by means of objective analysis and then least square fitted to obtain the annual and semiannual harmonics. At the sea surface a simple up- and down-gulf sinusoidal seasonal wind of 
$5 \mathrm{~m} \mathrm{~s}^{-1}$ amplitude is imposed with maximum up-gulf in August. Heat and fresh water fluxes were calculated with bulk formulae as in Castro et al. (1994) using the monthly meteorological data, from 7 stations around the gulf (also fitted to seasonal functions), and the calculated model SST. At the open boundary, radiation conditions were implemented (Orlanski, 1976; Chapman, 1985) on the dynamical variables and a sponge was also applied in the first 10 grid rows of the domain.

The model is started from rest, with a time step of $300 \mathrm{~s}$. It becomes periodically stable in three years; the results presented here were obtained from year four. While Marinone (2003) analyzes the model results by alternate choices of forcing agents, the results shown in this article come from the model forced with all of them, namely: (a) tides, (b) climatological hydrography at the mouth, (c) winds, and (d) heat and fresh water fluxes at the sea-air interface.

Finally, the trajectories were obtained by a standard bilinear interpolation of the velocity field at the particle position, with a second order Runge-Kutta scheme (e.g. Garcia, 1994).

At the coast, the normal velocity should be zero, i.e., $\mathbf{v} \bullet \mathbf{n}=0$, where $\mathbf{v}$ is the horizontal vector velocity and $\mathbf{n}$ the normal vector to the coast. To accomplish this, the first land point from the coast grid was assigned the negative value of that of the first sea grid point. When the particles reached the open boundary at the south, we stopped following them, i.e., we did not bring them back to the model domain. The particle trajectories were computed for two time periods of integration: a) a monthly period to get a view of the short time scale circulation throughout the year, and b) an annual period in order to obtain information of the circulation on the longest model time scale; twelve experiments were done starting at the beginning of each month. The particles were seeded one every other grid point for a total of 710 particles for each case. 


\section{Results}

\subsection{General circulation}

To synthesize the results, they are integrated by regions as shown in Figure 1. The particles are tagged according to their initial position as NP, IP, CP, and SP for the particles released at the northern (NR), island (IR), central (CR) and southern (SR) regions, respectively.

\subsubsection{Monthly trajectories}

Figure 2 shows the monthly trajectories for selected months of the year. The seasonal cycle will be described around these months. In the northern part of the gulf a gyre, anticyclonic from October to May (Fig. 2d, a) and cyclonic from July to August (Fig. 2c), was found. The anticyclonic gyre coexists with a smaller, elongated cyclonic gyre, located near the coast of Baja California (BC, hereafter). In the anticyclonic period, the particles to the east of Angel de la Guarda Island (hereafter AGI) separate in two groups, one returns to the northern region and the other one escapes to the south. Transition periods occur in June and September (not shown), and they differ from each other. In June, the particles just stop and start moving in the opposite direction. During September, two cyclonic gyres develop, one at the northeast of AGI, and the other further north near Wagner Basin.

Lavín et al. (1997) released Argos drifters in the northern region and found a gyre. Palacios et al., (2002), with the help of current meter data and geostrophic calculations described the annual cycle of the gyre. They found an anticyclonic gyre (Fig. 3a) lasting from November to April and a cyclonic one (Fig. 3c) lasting from June to September/October, with transition periods between 
regimes taking about three weeks each. The trajectories calculated from the model for March and September for the same area are shown in Figures $3 b$ and $3 d$, respectively. The trajectories from the model are in good agreement with the Argos drifters.

According to the model, the center and southern regions have two periods of anticyclonic circulation, but only one of cyclonic circulation throughout the year. The anticyclonic periods occur from October to November (Fig. 2d), and in May (Fig. 2b); the cyclonic period occurs at the same time as that in the northern region, i.e., from July to August (Fig. 2c). From January to March (Fig. 2a) the particles are advected to the mouth due to the wind induced currents. From June to September (Fig. 2.c), the particles flow in the opposite direction but over the continental coast. During these months (January-March and June-September) the number of particles travelling outside and into the gulf is maximum, respectively. In the October to November (anticyclonic) period, a couple of gyres are observed over the deeper basins, but not in the May period. There are four transition periods characterized by an intense flow of particles on the continental coast: out of the gulf during December and April and into the gulf during June and September. At the BC coast, the particles move slowly in the opposite direction.

Finally, in the IR there are narrow channels and drastic bathymetric changes where larger currents develop. Beier (1997) found long periods of no communication between the northern and southern regions. In this work, we found communication all year long through the channels between Angel de la Guarda and Tiburon islands. This exchange is inhibited only when the circulation is anticyclonic (i.e. May and October/November) in both the northern and southern regions (Fig. 2b, d). In the Ballenas channel, the trajectories are short, and the communication is minimal. During 
the transition periods small gyres develop between Angel de la Guarda Island and the continental coast.

Summarizing (see Table 1), the northern region circulation is anticyclonic from October to May, and cyclonic from July to August, and the transitions periods are in June and September. In the central and southern regions two anticyclonic periods appear, in May and from October to November, and just one cyclonic from July to August. Transition periods occur in December, April, June and September, with particles flowing to the southern region in the first two and to the northern gulf in the last two. From January to March the particles are advected outside the gulf in this area.

\subsubsection{Annual trajectories}

To gain insight into the way the drifters travel within the gulf, particles were advected for a year. Twelve annual experiments were done, each one starting on the first day of each month. Figure 4 shows twelve snapshots of the experiment started on January 1, 2001. To help identify the origin of the different particles, the NP are marked as $\mathrm{O}$, the IP as + , the $\mathrm{CP}$ as $\diamond$ and the SP as *, respectively, and the streak behind the mark shows the five-day history of the particles.

The initial condition for this experiment corresponds to the anticyclonic period in the northern region, and in the southern and central regions to the period of particle expulsion. In this experiment the northern region and the Baja California coast capture particles. The northern region releases particles during the anticyclonic period (Fig. 4c-e) but most of them return to the north in the cyclonic period (Fig. 4f-g); few particles from the north cross the mouth of the gulf in April and 
May. As seen in the previous section, the passing of particles between the northern and central regions across the islands region is mostly between Angel de la Guarda and Tiburon islands. Meanwhile Ballenas channel captures particles during the anticyclonic period (Fig. 4a-f) and releases them during the cyclonic period (Fig. 4g-h). In the central and southern regions, two zones are clearly identified: (a) the Baja California coast which captures particles during the experiment and release them in the anticyclonic period, and (b) the continental coast which always acts as a transit zone.

To see the routes and final fate in all the experiments, contours of the escape time from the gulf by the particles were calculated (Fig. 5), and typical routes of the particles were identified (color lines in Fig. 5) inside each area or region. Three groups out of the 12 experiments resulted. The first group includes the experiments with initial conditions from June to September. Fig. 5a shows the case starting on July 1, 2001. During the first three months, a small group of particles escapes out of the gulf, from close to its mouth, following the red line close to $\mathrm{BC}$. The next group escapes between six and eight months after the experiments start, that is, between December and February. This group is located in the central region near the coast of $\mathrm{BC}$, but the particles move to the continental coast from October to November, and then escape from the gulf (see orange line in Fig. 5a). The rest of the particles that escape the gulf take between eight and ten months. These particles first follow the continental coast to the head (the yellow line) during the cyclonic period, and by October (during the anticyclonic period) the particles return to the central region, always following the continental coast, and then they escape. Most of the particles that started the experiment in the northern region of the gulf (green line) remain there during the whole experiment trapped on the gyre. Some of the particles in the central and southern region stay inside the gulf during the 
experiment too; most of them (blue line) travel to the northern region and are trapped there by the gyre.

The second group of experiments includes those starting between October and March and are represented by the one started on January 1, 2001 (Fig. 5b). In these experiments the particles near the continental coast of the gulf quickly escape in the first three months (red, orange and yellow lines). The particles near the continental coast in the northern region are the next to escape (green line); these particles follow the coast and exit the gulf in three to five months. The particles that started the experiment in the northern region and in the central region over the Baja California coast remain inside the gulf throughout the experiment. These particles are trapped by the gyre in the northern region (blue line), or move in a closed circuit (purple line) along the gulf.

Finally, the third group includes the experiments between April and May, represented by the one starting on April 1, 2001 (Fig. 5c). In this case, only the particles near the mouth escape in less than two months (red and orange lines). The next group to escape is the one located near the continental coast of the northern region (yellow line). In the first months these particles travel up to the north and then return following the coast, crossing the boundary eleven months later. The particles of the northern (green line) and central (blue line) regions remain inside the gulf trapped by the gyre throughout the experiment.

\subsection{Regional analysis}

We found that during the cyclonic period, particles are advected from the central and southern regions to the northern one and that during the anticyclonic period the particles escape from the 
gulf. With the purpose of analyzing this exchange process of particles among the different regions, we quantified the number of particles by region and by month. Two examples will be shown, namely those started in April and October. They were chosen because they start two months before the start of the cyclonic and anticyclonic periods, respectively, when the maximum number of particles is expected to be inside the gulf. The quantification was done keeping the label of the origin of the particles. Initially there were 149, 182, 232 and 147 particles seeded for the NR, IR, CR and SR, respectively. For each month, there are 4 bars, one for each region (in the same order) with the number of particles contained in each region on the last day of the month. For each bar, there are four stacks indicating the number of particles present in that zone that originated in different regions.

During the first three months of the experiment started in April 1 (fig. 6a) few changes happen, the particles just disperse into the surrounding areas. By June, the particles move from the SR, to the CR, and from there to the NR. By July the number of particles increases from 182 to 242 and from 149 to 190 in the IR and NR, respectively ( $30 \%$ in each region). The maximum number of particles in the northern region occurs between August and October with 316, 335, and 324 particles, respectively ( $20 \%$ from the CR and SR, $40 \%$ from the NR, and $40 \%$ from the IR). After October, the number of particles in the northern region decreases, and by December the initial number of particles is reached again; by the end of the experiment there are only 61 (of 149) particles in the northern region. The number of particles of the CR and SR decrease from July until November and increase from there to the end of the experiment, with particles from the NR and IR. In this case very few particles from the NR and IR have escaped the gulf by the end of the experiment. 
The experiment starting on October 1 (Fig. 6b) begins just before the anticyclonic period. The expulsion of particles from the gulf begins in December and increases in the next months. In January $32 \%$ (48 of 149) of NP reach the central region, in February $13 \%$ (20 of 149) reach the southern region, and $8 \%$ (12 of 149) cross the open boundary. The particles from the island region separate in three groups of approximately 50 particles. One group moves to the northern region, another to the central one (which then escapes from the gulf between December and March), and the third group remains in the islands' region. The central region maintains the total number of particles in the first two months, with particles coming from the northern and island regions replacing those that escape from the gulf. By January there are just 148 particles (48 NP, 15 IP, 51 $\mathrm{CP}$, and $34 \mathrm{SP}$ ), which is only $57 \%$ of those originally seeded in this region. By March, there are only 65 particles (20 NP, $6 \mathrm{IP}, 25 \mathrm{CP}$, and $14 \mathrm{SP}$ ) in the CR, which is less than $28 \%$ of the initial number.

\subsection{Indices}

Three indices were calculated with the monthly trajectories:

- TD: Travel Distance of the particle along the trajectory (including the tidal excursion)

- TDf: as TD but by applying a low pass filter to the path (this index is very similar to the net distance traveled by a particle, which is not shown)

- RT: Residence Time required by a particle to leave a circular area of radius $\mathrm{R}(\mathrm{R}=50,100$, and $150 \mathrm{~km}$ were used but only the $50 \mathrm{~km}$ case will be shown) 
These indices were calculated for all the trajectories and assigned to the initial position of the particle. Notice that the property contoured on the map is a property of the trajectory, not of the initial position. The indices are different for each experiment, but the experiments from January and July are representatives of the anticyclonic and cyclonic periods, and these are described next.

Anticyclonic period. The indices calculated for this period are shown in Figure 7. TD ranges between 600 and $200 \mathrm{~km}$. In the northern region the particles near the coast have TD $>400 \mathrm{~km}$, while those near the center move less, TD $<300 \mathrm{~km}$ (Fig. 7a).

In the central and southern regions TD and TDf are similar (Fig. 7a, b), this means that the tidal excursion of the particles is small; or in other words, that the movement of the particles is dominated by the large scale circulation and the tide plays a smaller role than in the northern region.

The RT index (Fig. 7c) shows that on the continental coast the particles travel more than $150 \mathrm{~km}$ in less than 20 days. The particles get trapped by $\mathrm{R}=50 \mathrm{~km}$ for at least $20-25$ days only on the gyre in the northern region, and on the Baja California coast in the central and southern regions.

Cyclonic period. The indices calculated for this period are shown in Fig 8. As it was observed above, during the cyclonic period the largest number of particles move into the gulf (Fig. 2g-h), and this fact is reflected in having the largest distances $(\mathrm{TD}>350 \mathrm{~km})$ traveled by the particles in the gulf (except on the Baja California coast where the particles travel less than $150 \mathrm{~km}$ [Fig. 8a]). If the tide is eliminated (TDf Fig. 8b), the distance diminishes for the northern and islands regions 
from $400 \mathrm{~km}$ to $200 \mathrm{~km}$. In the southern region, the difference between TD and TDf is not as large as during the anticyclonic period. The RT (Fig. 8c) index shows that for the central region, near the continental coast, the particles travel more than $150 \mathrm{~km}$ in 15 days $\left(11.5 \mathrm{~cm} \mathrm{~s}^{-1}\right)$. The northern part of the gulf captures particles for more than 30 days in $R=150 \mathrm{~km}$, and in $\mathrm{R}=50 \mathrm{~km}$ at the center of this region. The Baja California coast captures particles in a radius of $50 \mathrm{~km}$ for more than 25 days.

\section{Conclusions}

The surface Lagrangian circulation of the Gulf of California was studied by advecting particles for monthly and annual periods using the results of the 3D numerical model of Marinone (2003). The circulation in the northern region of the gulf is anticyclonic from October to May and cyclonic during July and August, and is dominated by a gyre on the center of the region. These results coincide with the available current data reported by Lavín et al., (1997) and Palacios et al., (2002) from the northern region. On the central and southern regions, two anticyclonic periods in May, and from October to November, and a cyclonic period during July to August, were found. This semiannual character of the Lagrangian circulation is due to the hydrographic forcing of the numerical model (Marinone, 2003). The different scales of variability are determined by the forcing in the Eulerian numerical model which are due to the tides, wind and heat fluxes, and the Pacific Ocean, i.e., hours, semiannual and annual periods, respectively.

The northern region captures particles for more than 30 days within a $150 \mathrm{~km}$ radius. During the cyclonic period, the particles arrive from the central and southern regions, doubling the number of 
particles in the northern region. The opposite process is observed during the anticyclonic period; particles moving to the central and southern regions, but most of these particles return to the northern part in the cyclonic period. The principal gyre located on the center of the northern region captures particles for more than 30 days in a radius of $50 \mathrm{~km}$. Velasco Fuentes and Marinone (1999) found, with a simpler 2D barotropic model, the same result.

Ballenas channel traps particles for most of the year. The exchange of particles between the northern and central region occurs largely through the channel between Angel de la Guarda and Tiburon islands. These regions keep communicated during the year, except when there are anticyclonic circulation in the whole gulf (i.e. May, and from October to November). When the gulf maintains a cyclonic circulation, this region develops some small gyres. In addition, an anticyclonic permanent gyre at the south of Tiburon Island was found. This gyre captures particles for more than 10 days in $\mathrm{R}=50 \mathrm{~km}$.

The central region is divided in two zones: one near to $\mathrm{BC}$ and the other on the continental coast. The first one acts as a trapping area for most of the year, where the particles travel less than $100 \mathrm{~km}$ in 30 days. From this zone the particles escape only during the anticyclonic period. The second zone is an escape zone where most of the particles rapidly pass through (as obtained also by Velasco Fuentes and Marinone, 1999). In this zone, the particles travel $50 \mathrm{~km}$ in less than 5 days when the flow is to the exterior and $50 \mathrm{~km}$ in 10 days when the flow is to the interior of the gulf. Also, cyclonic gyres were found in the zone from July to August and anticyclonic gyres in November. 
Finally, it was found that the effect of the tide in the determination of the trajectories is not important in the central and southern regions where the tidal excursion is small compared to the advection of the large-scale circulation. In the island and northern regions, the tidal excursion of the particles is important.

Future work will focus on shorter time scales with initial conditions (time and space) located over/near areas of biological importance. For example, shrimp fisheries in the gulf are important and the time from spawn to postlarvae is about 2-3 weeks, when they have motile capabilities to search for a favorable habitat (Calderon-Aguilera, et al., 2003); before this time, the migration patterns of the eggs and larvae depends critically on the circulation. Studies like the present one can be very useful to predict the possible migration patterns of these organisms and can help to better manage the fishery. Of course, a more realistic study will require the use of the full 3D-velocity field because spawning occurs at the seabed.

Acknowledgments: This research was financed by CONACyT, through grant 35251-T and by CICESE's regular budget. The comments of two anonymous reviewers helped to improve previous versions of this paper. We thank Miguel Lavín and Edgar Pavía for critically reading the manuscript.

\section{References}

Backhaus, J. O., 1983. A semi-implicit scheme for the shallow water equation for application to shelf sea modelling. Continental Shelf Research 2, 243-254.

Backhaus, J. O., 1985. A three-dimensional model for the simulation of shelf sea dynamics. Deutsche Hydrographische Zeitschrift 38, 165-187.

Badan-Dangon A., C. E. Dorman, M. A. Merrifield, and C. D. Winant, 1991. The lower atmosphere over the Gulf of California. Journal of Geophysical Research 96, 16,87716,896 . 
Bartsch, J., 1993. Application of a circulation and transport model system to the dispersal of herring larvae in the North Sea. Continental Shelf Research 13(12), 1335-1361.

Beier, E. A numerical investigation of the annual variability in the Gulf of California. Journal of Physical Oceanography, 27, 615-632, 1997.

Beier, E., 1999. Estudio de la marea y la circulación estacional en el Golfo de California mediante un modelo de dos capas heterogéneas. PhD thesis, CICESE, Ensenada, B. C., México,unpublished.

Berón-Vera, F. J. and P. Ripa. Three-dimensional aspects of the seasonal heat balance in the Gulf of California. Journal of Geophysical Research 105, 11,441-11,457, 2000.

Berón-Vera, F. J. and P. Ripa, 2002. Seasonal salinity balance in the Gulf of California. Journal of Geophysical Research 107(8), 15,1-15.

Bray, N. A. Thermohaline Circulation in the Gulf of California, 1988. Journal of Geophysical Research 93, 4,993-5,020.

Calderón-Aguilera, L. E., S. G. Marinone and E. A. Aragón, 2003. Influence of oceanographic processes on the early life stages of the blue shrimp (Litopenaeus stylirostris) in the upper gulf of California. Journal of Marine Systems 39, 117-128.

Carrillo, L. E., M. F. Lavín and E. Palacios-Hernández, 2002. Seasonal evolution of the geostrophic circulation in the northern Gulf of California. Estuarine, Coastal and Shelf Sciences 54, 157-173.

Castro, R., 2001. Variabilidad termohalina e intercambios de calor, sal y agua en la entrada al Golfo de California. $\mathrm{PhD}$ thesis, UABC, Ensenada,México, unpublished.

Castro, R., M. F. Lavín, and P. Ripa, 1994. Seasonal heat balance in the Gulf of California. Journal of Geophysical Research 99, 3249-3261.

Chapman, D. C., 1985. Numerical treatment of cross-shelf open boundaries in a barotropic coastal ocean model. Journal of Physical Oceanography 15, 1060-1075.

Collins, C. A., N. Garfield, A. S. Mascarenhas, M. G. Spearman, and T. A. Rago, 1997. Ocean currents across the entrance to the Gulf of California. Journal of Geophysical Research 102, 20,927-20,936.

Crean, P. B., T. S. Murty, and J. A. Stronach, 1988. Mathematical Modelling of tides and estuarine circulation. Springer, New York, 471 pp.

García, A. L., 1994. Numerical methods for physics. Prentice Hall, Englewood Cliffs, New Jersey. pp. 64-70.

Lavín, M. F., R. Durazo, E. Palacios, M. L. Argote, and L. Carrillo, 1997. Lagrangian observations of the circulation in the northern Gulf of California. Journal of Physical Oceanography 27, 2298-2305.

Marinone S. G., 2003. The mean and seasonal circulation in a three dimensional model of the Gulf of California. Journal of Geophysical Research, submitted.

Marinone, S. G., S. Pond, and J. Fyfe, 1996. A three-dimensional model of tide and wind-induced residual currents in the Central Strait of Georgia, Canada. Estuarine, Coastal and Shelf Sciences, 43, 157-182.

Orlanski, I., 1976. A simple boundary condition on unbounded hyperbolic flows. Journal of Computational Physics 21, 251-269.

Paden, C. A., M. R. Abbott, and C. D. Winant, 1991. Tidal and Atmospheric Forcing of the Upper Ocean in the Gulf of California, 1. Sea Surface Temperature variability, Journal of Geophysical Research 96, 18,337-18,359. 
Palacios-Hernández, E., E. Beier, M. F. Lavín and P. Ripa, 2002. The effect of the seasonal variation of stratification on the circulation on the northern Gulf of California. Journal of Physical Oceanography 32, 705-728.

Peterman R. M., Marinone, S. G., Thompson, K. A., Jardine, I. D., Crittenden, R. N., Leblond, P. H., and Walters, C. J., 1994. Simulation of juvenile sockeye salmon (Oncorhynchus nerka) migrations in the Strait of Georgia, British Columbia. Fisheries Oceanography 3:4, 221-235.

Rady, M. A., M. I. El-Sabh, T. S. Murty, and J. O. Backhaus, 1998. Residual circulation in the Gulf of Suez, Egypt. Estuarine, Coastal, and Shelf Sciences, 46, 205-220.

Roden, G. I., 1972. Thermohaline structure and baroclinic flow across the Gulf of California entrance and in the Revillagigedo Island region. Journal of Physical Oceanography 2, 177183.

Ripa, P., 1990. Seasonal circulation in the Gulf of California. Annales Geophysicae, 8, 559-564.

Ripa, P., 1997. Toward a physical explanation of the seasonal dynamics and thermodynamics of the Gulf of California. Journal of Physical Oceanography 27, 597-614.

Stronach, J. A., J. O. Backhaus, and T. S. Murty, 1993. An update on the numerical simulation of oceanographic processes in the waters between Vancouver Island and the mainland: the GF8 model. Oceanography and Marine Biology: an Annual Review, 31, 1-86.

Velasco Fuentes, O. U., and Marinone, S. G., 1999. A numerical study of the Lagrangian circulation in the Gulf of California. Journal of Marine Systems 22, 1-12. 


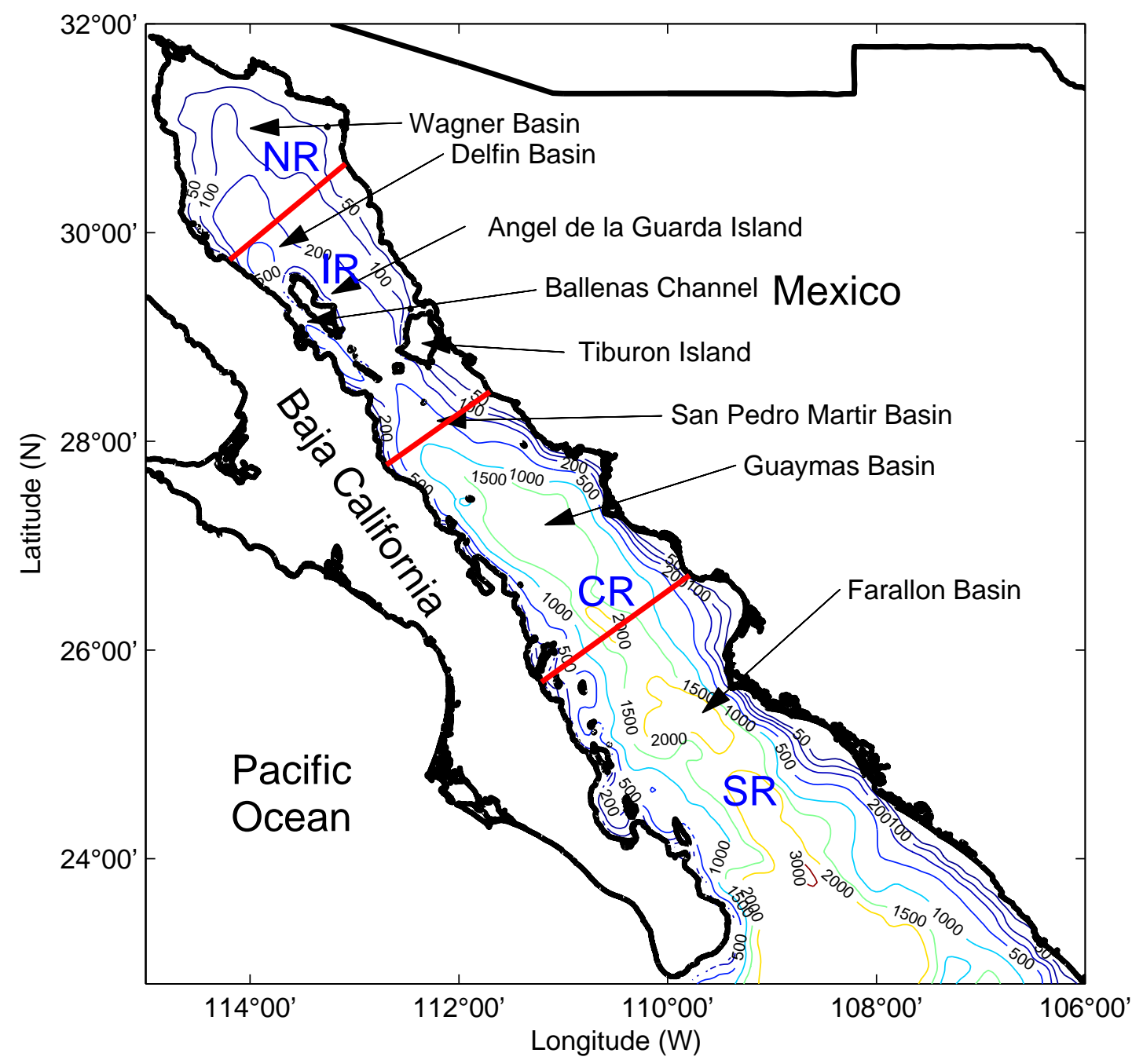

Figure 1. Plan view and bathymetry (in meters) of the Gulf of California. The gulf is divided in northern, island, central and southern regions and are referred as NR, IR, CR, and SR, respectively. 

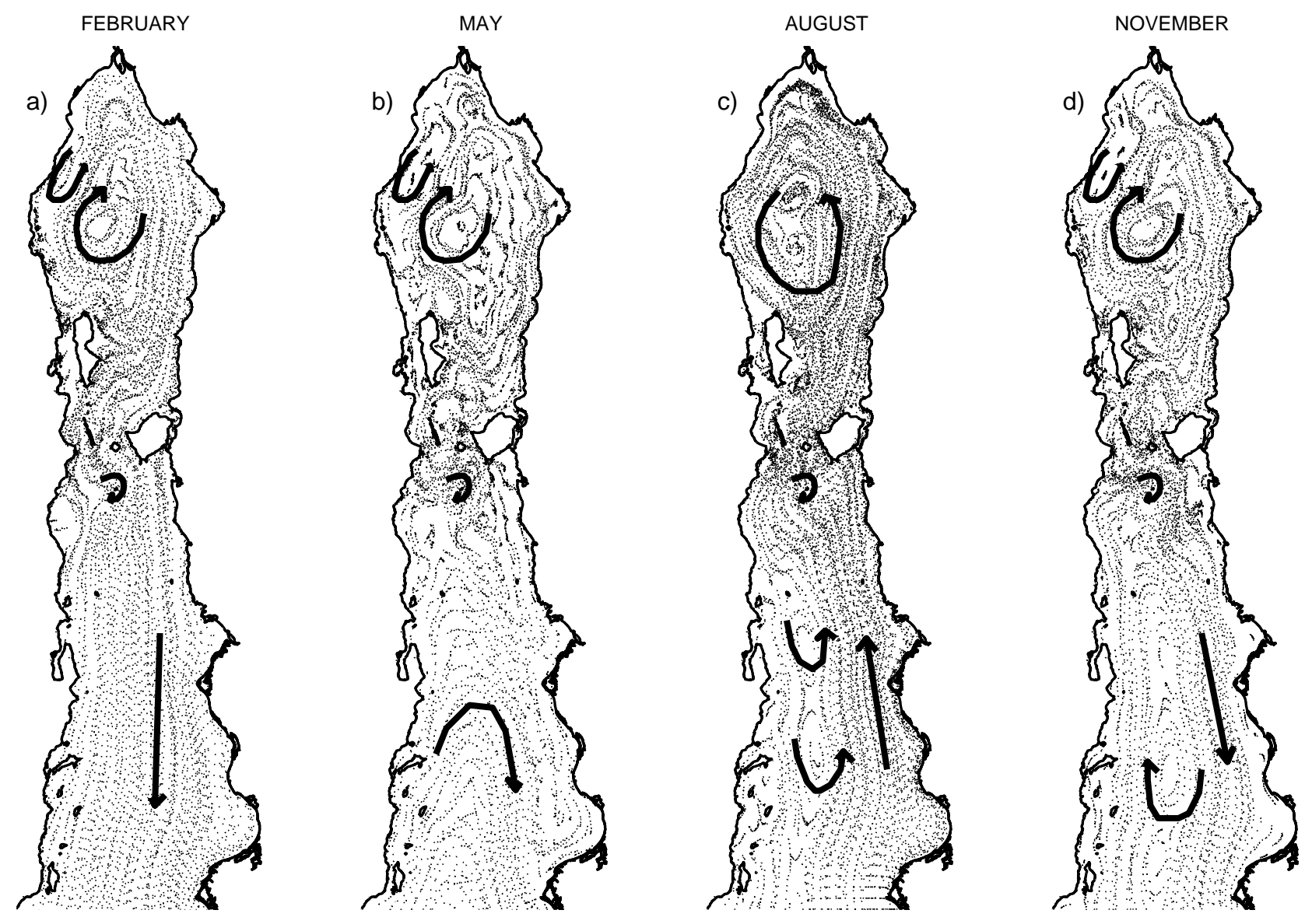

Figure 2. Monthly trajectories of particles in the Gulf of California for the indicated month. The heavy lines indicate the main direction of the trajectories. 

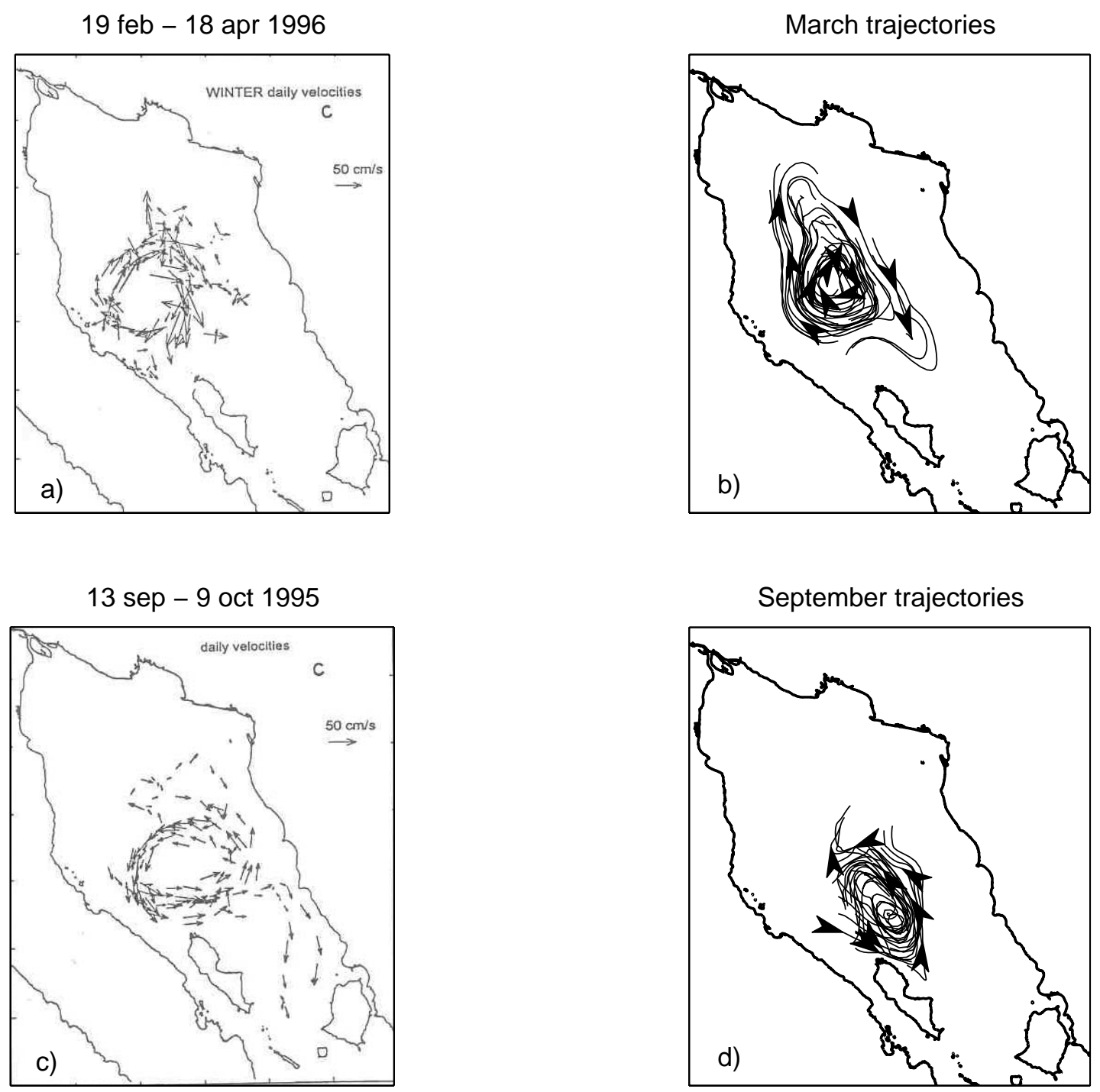

Figure 3. Comparison between the Argos Drifters measured by Lavín et al. (1997) and the simulated trajectories. For the anticyclonic period the trajectories a) measured for February 19 to April 18, 1996 and b) simulated during March. For the cyclonic period the trajectories c) measured for September 13 to October 9, 1995 and d) simulated during September. 

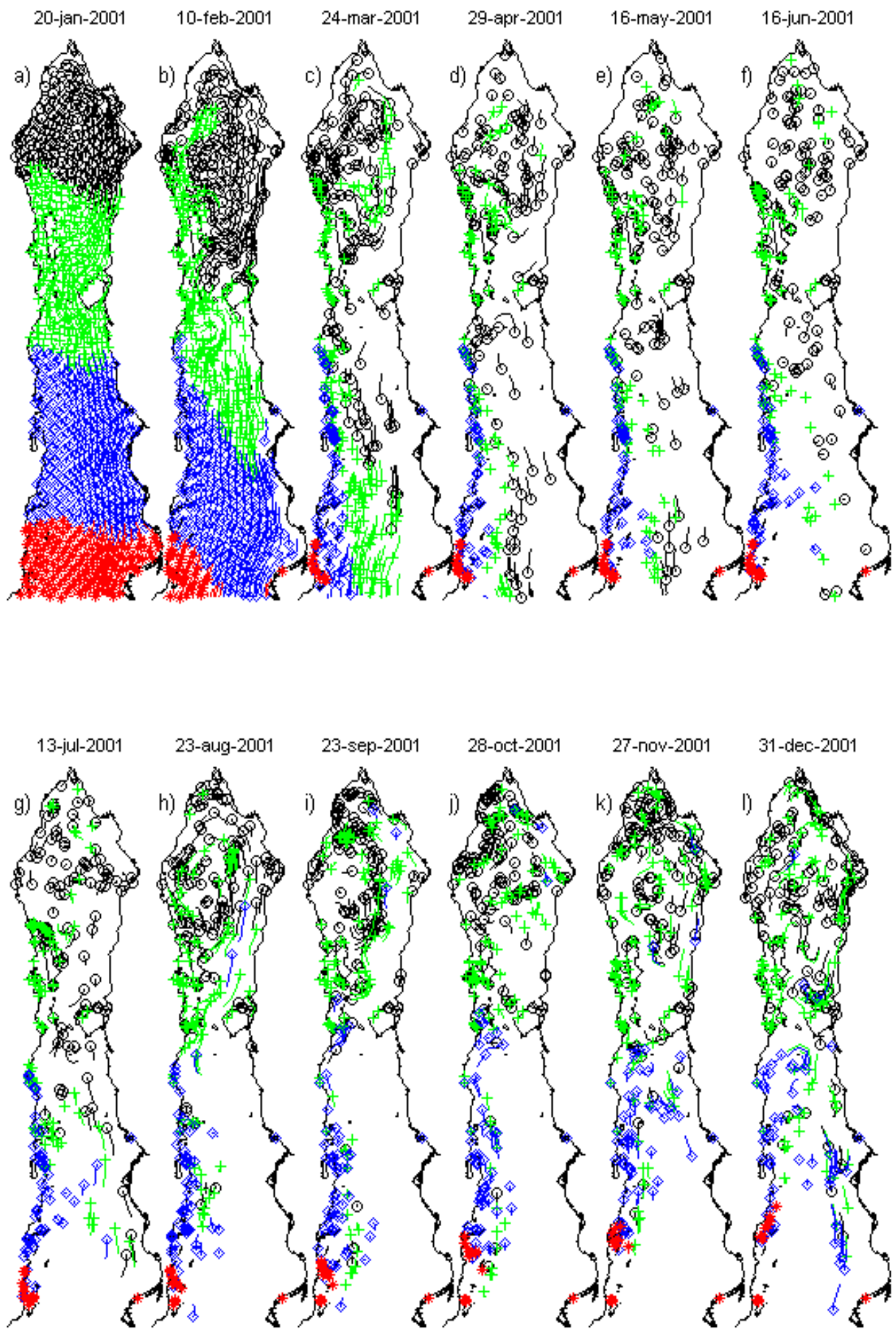

Figure 4. Time series of the trajectories for the experiment started at January 1, 2001. Particles seeded in the northern, island, central, and southern regions are marked as $\bigcirc,+, \diamond$ and *, respectively. The streak behind each particle shows the five-day path. 

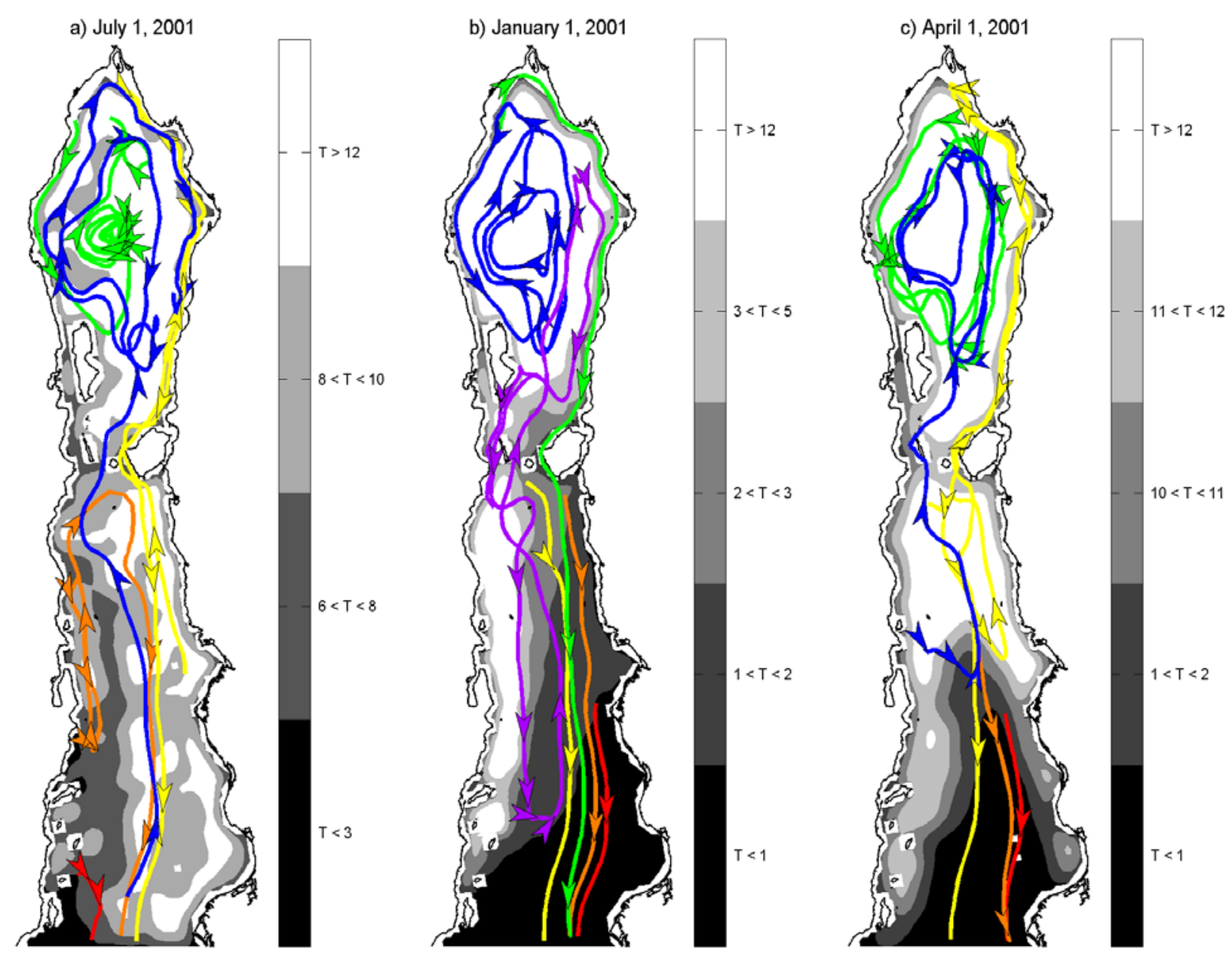

Figure 5. Contour plot of the escape time (from the gulf) of the particles. The gray scale is in months. The lines show the main routes used by the particles. The experiments started on a) July 1, b) January 1, and c) April 1. 


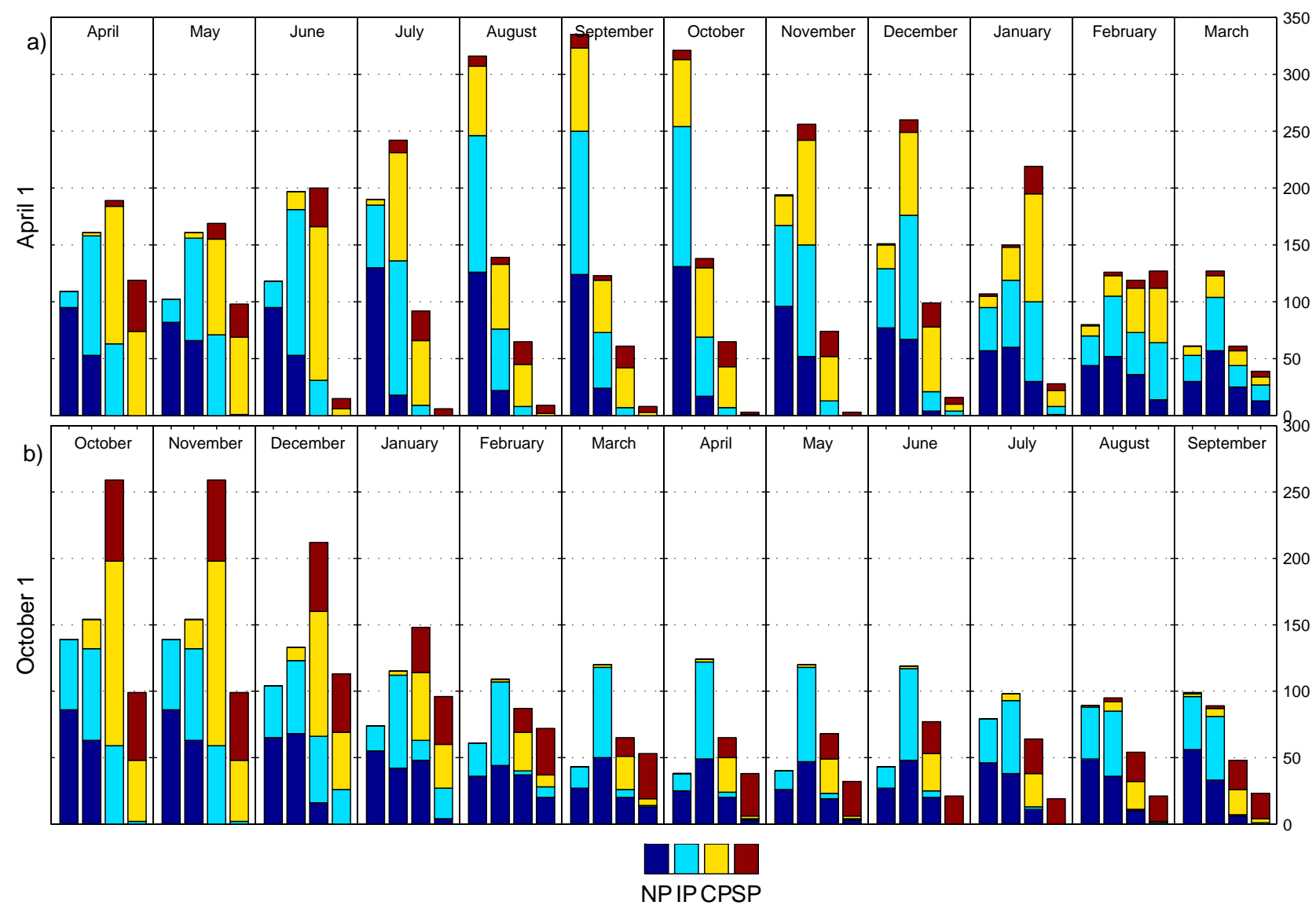

Figure 6. Series of bar plots showing the number of particles in each region for the experiments starting on a) April 1, and b) the October 1. Four bars are shown for each month, one for each region (NR, IR, CR, and SR). For each bar, four stacks label the number of particles that started at the different regions. 

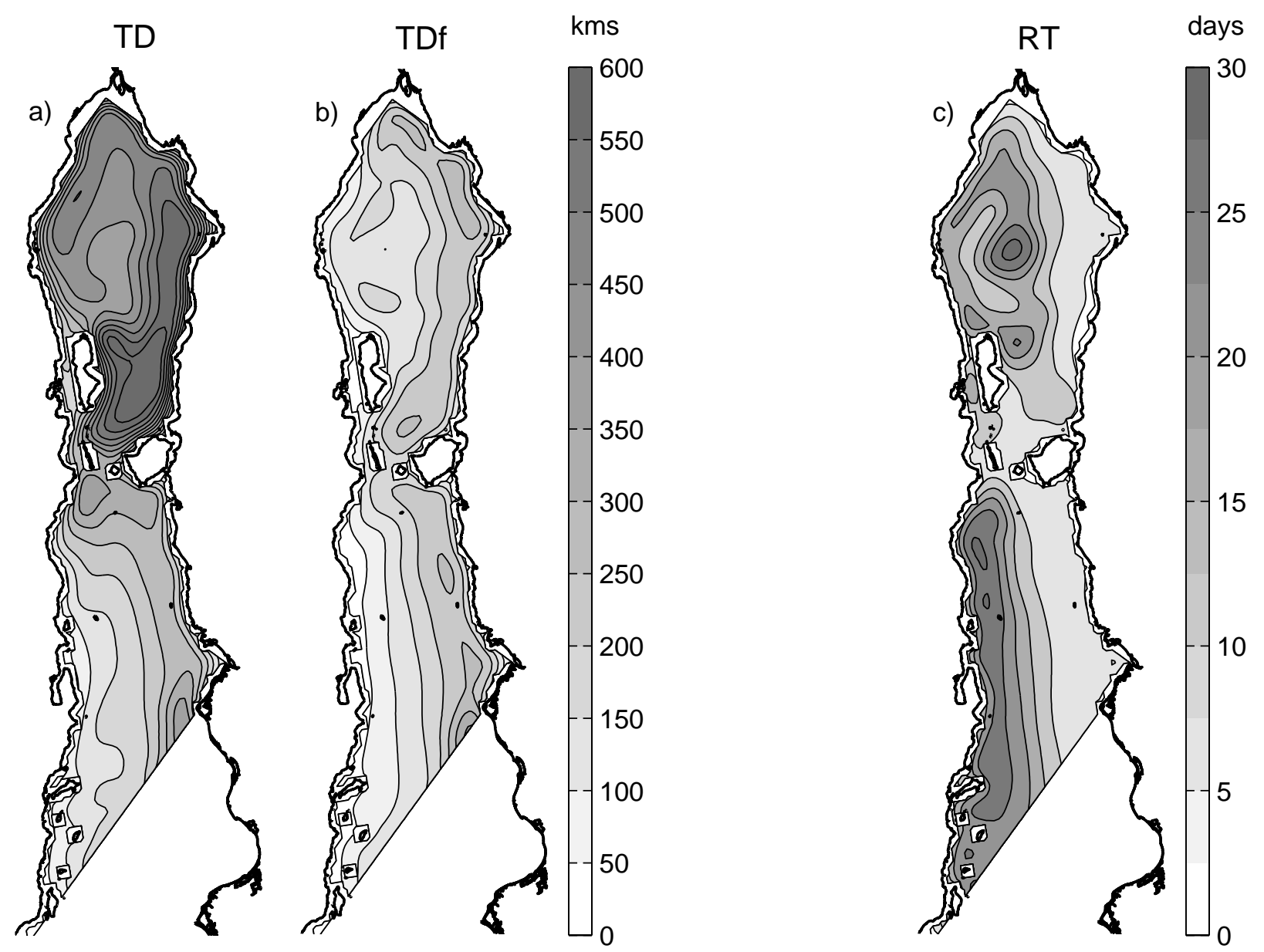

Figure 7. Indices of the particles trajectories for January (representative of the anticyclonic period) of (a) Travel Distance (TD), (b) Travel Distance without the tide (TDf), and (c) Residence Time within a radius of $50 \mathrm{~km}(\mathrm{RT})$. 

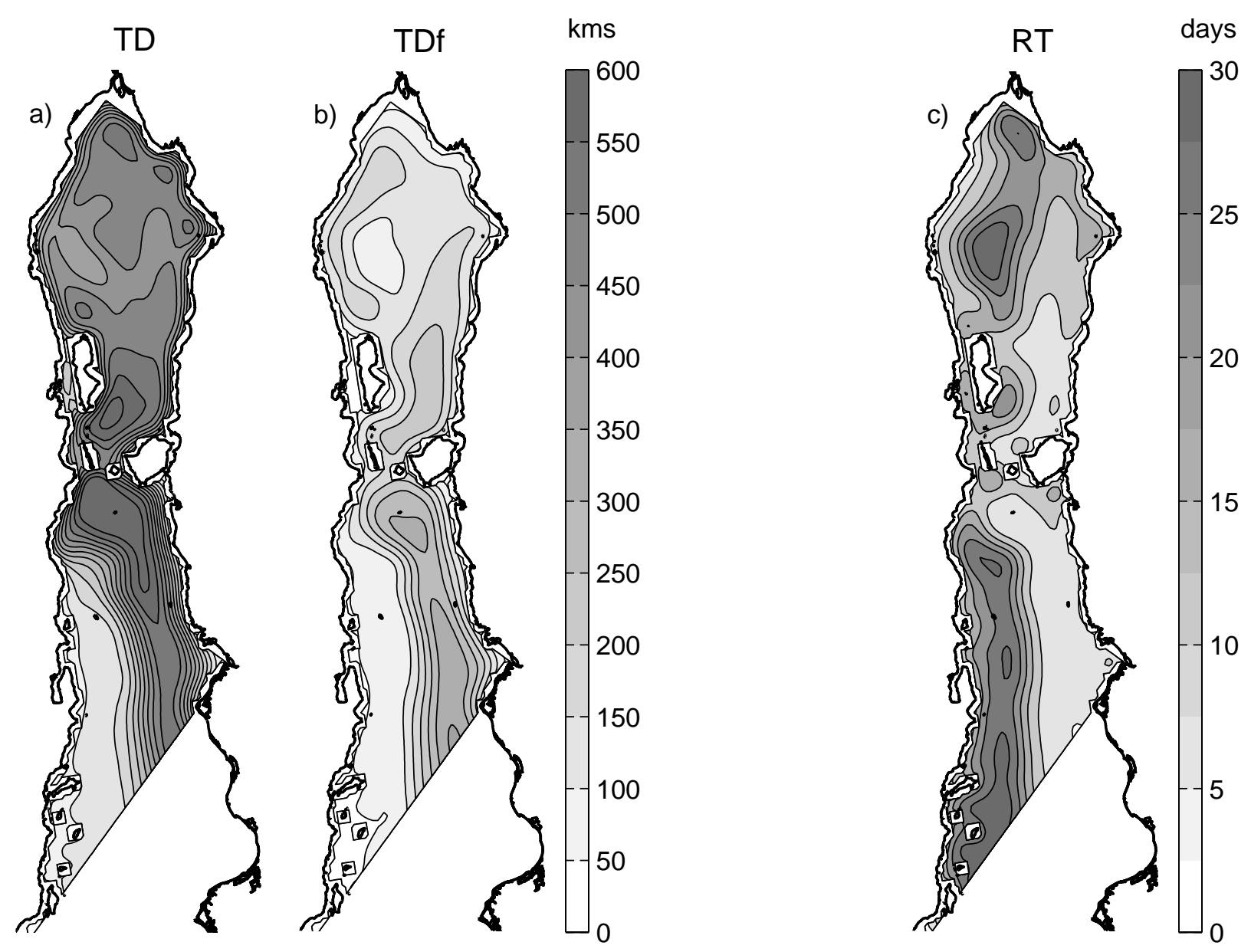

Figure 8. Some as Figure 7 but for the July monthly trajectories (representative of the cyclonic period). 